\title{
Metabolism of poplar salicinoids by the generalist herbivore Lymantria dispar (Lepidoptera)
}

G. Andreas Boeckler ${ }^{1 *}$, Christian Paetz ${ }^{2}$, Peter Feibicke ${ }^{1}$, Jonathan Gershenzon ${ }^{1}$ \& Sybille B. Unsicker ${ }^{1^{*}}$

${ }^{1}$ Department of Biochemistry, Max Planck Institute for Chemical Ecology, Hans-Knöll Str. 8, 07745 Jena, Germany

${ }^{2}$ Biosynthesis / NMR Research group, Max Planck Institute for Chemical Ecology, Hans-Knöll Str. 8, 07745 Jena, Germany

${ }^{*}$ corresponding authors:

G. Andreas Boeckler, aboeckler@ice.mpg.de

Sybille B. Unsicker, sunsicker@ice.mpg.de, +49(0)3641 571328 


\section{Abstract}

The survival of insect herbivores on chemically defended plants may often depend on their ability to metabolize these defense compounds. However, only little knowledge is available on how insects actually process most plant defense compounds. We investigated the metabolism of salicinoids, a major group of phenolic glycosides in poplar and willow species, by a generalist herbivore, the gypsy moth (Lymantria dispar). Seven salicinoid metabolites identified in gypsy moth caterpillar feces were mostly conjugates with glucose, cysteine or glycine. Two of the glucosides were phosphorylated, a feature not previously reported for insect metabolites of plant defense compounds. The origins of these metabolites were traced to specific moieties of three major poplar salicinoids ingested, salicin, salicortin and tremulacin. Based on the observed metabolite patterns we were able to deduce the initial steps of salicinoid breakdown in L. dispar guts, which involves cleavage of ester bonds. The conjugated molecules were effectively eliminated within $24 \mathrm{~h}$ after ingestion. Some of the initial breakdown products (salicin and catechol) demonstrated negative effects on insect growth and survival in bioassays on artificial diets. Gypsy moth caterpillars with prior feeding experience on salicinoid-containing poplar foliage converted salicinoids to the identified metabolites more efficiently than caterpillars prefed an artificial diet. The majority of the metabolites we identified were also produced by other common poplar-feeding insects. The conversion of plant defenses like salicinoids to a variety of water-soluble sugar, phosphate and amino acid conjugates and their subsequent excretion fits the general detoxification strategy found in insect herbivores and other animals.

Keywords: Catechol glycoside, Detoxification, Hippuric acid, $N$-acetyl cysteine conjugates, Phenolic glycosides, Phosphorylated glycosides, Poplar defense, Salicinoids. 
The host plants of insect herbivores often contain high quantities of chemical defense

3

4

5

6

compounds. However, the mechanism by which insects avoid the toxic effects of these compounds is known in just a few cases (Després et al., 2007; Heidel-Fischer and Vogel, 2015). Insects may avoid feeding on plant parts with high concentrations of chemical defenses (Shroff et al., 2008), or rapidly excrete compounds after ingestion (Sorensen and Dearing, 2006). In addition, they may possess altered target sites that are no longer susceptible to the toxic action of the defense compound (Zhen et al., 2012), or may sequester compounds in a way that avoids intoxication (Opitz and Müller, 2009). Yet most attention has been paid to metabolic transformations that allow herbivores to detoxify defenses and excrete the resulting metabolites (Heckel, 2014; Novoselov et al., 2015). Research on herbivore detoxification of plant defense compounds and insecticides is based on the vast literature on drug metabolism in humans and other animals. Three major phases of detoxification have been described: the initial oxidation, reduction or hydrolysis of the toxin to introduce polarity or a reactive site (Phase I), conjugation with a polar molecular such as glucose, sulfate, glycine or glutathione (Phase II), and excretion (Phase III).

Insect herbivores have been frequently shown to metabolize plant defense compounds, but the identity of the metabolites is usually unknown. Genes induced upon exposure to defense compounds have been identified that encode proteins from families of known detoxification enzymes, including cytochrome P450 monooxygenases (Giraudo et al., 2015), carboxylesterases (Lu et al., 2015), UDP-glucosyl transferases (Ahn et al., 2012) and glutathione S-transferases (Zhang et al., 2012), but the reaction products have rarely been identified (Heidel-Fischer and Vogel, 2015). Additionally, recent studies have raised concerns that mRNA expression profiles are not always well correlated with detoxification activities (du Rand et al., 2015). More information about the pathways by which plant defenses are metabolized would increase our knowledge about why insects are able to exploit some plants, but not others. Even if it is not always clear if a specific metabolite results from a genuine detoxification reaction, the structure can provide valuable information about the mode of action of the defense compound.

Phenolics are one of the largest group of plant defense compounds, especially in woody plants, but their metabolism by insect herbivores is little studied (Heckel, 2014). In willows and poplars, the major anti-herbivore defenses consist of the salicinoids, a group of phenolic glycosides with a core structure of a salicyl alcohol glucoside called salicin to which a variety 
of organic acids are esterified (Abreu et al., 2011; Boeckler et al., 2011). The negative impact of salicinoids on the performance of generalist herbivores is well documented for various species, including Papilio glaucus (Lindroth, 1991), Choristoneura conflictana (Clausen et al., 1989), Malacosoma disstria and Lymantria dispar (Hemming and Lindroth, 1995) or Operophtera brumata (Ruuhola et al., 2001). Salicinoids are activated defenses, that is they are non-toxic as stored in the plant, but are activated after ingestion. Plant endogenous enzymes are often essential for the activation of plant defenses, however, in case of salicinoids activation may be carried out spontaneously (Ruuhola 2003) and by plant enzymes, such as beta glucosidases (Lindroth 1988 Hydrolysis of phenolic glycosides by beta glucosidases in papilio glaucus subspecies) or polyphenol oxdidases (Haruta 2001 Polyphenol oxidase and herbivore defense in trembling aspen (Populus tremuloides): cDNA cloning, expression, and potential substrates. Salicinoids have been suggested to be activated by degradation to the toxic metabolite saligenin (reviewed in Pentzold et al., 2014) or catechol, which may oxidize to form reactive quinones (Ruuhola et al., 2001). These reactions were proposed based on the results of in vitro experiments (Clausen et al., 1990; Julkunen-Tiitto and Meier, 1992; Ruuhola et al., 2003) and studies with bacteria (Sonowal et al., 2013; Zhu et al., 1998) or vertebrates (Knuth et al., 2013; McLean et al., 2001), but the pathways of salicinoid metabolism in poplar-feeding arthropods are still not elucidated.

We investigated salicinoid metabolism in caterpillars of the gypsy moth (L. dispar), a generalist lepidopteran herbivore. Poplars are among the natural host plants of this insect and can suffer heavy defoliation during gypsy moth outbreaks (Lindroth, 1991). In this study, we identified a series of salicinoid metabolites found in the feces of gypsy moth caterpillars. By administering different types of salicinoids, the origin of the fecal metabolites was traced to specific structural features of the parent molecule. We also investigated the efficiency of salicinoid conversion to these metabolites in gypsy moth larvae, their distribution in the insect after poplar feeding, and the effect of salicinoid degradation products on caterpillar growth and survival. 


\subsection{Insect, plants and artificial diet}

Gypsy moth (Lymantria dispar) caterpillars were hatched from eggs (kindly provided by Hannah Nadel APHIS, USDA, USA) and reared on artificial gypsy moth diet (MP Biomedicals, Illkirch, France) as previously described (Boeckler et al., 2013) until they reached the $4^{\text {th }}-5^{\text {th }}$ instar. The wheat germ diet was also used for experiments where individual chemicals were tested. The diet was prepared using 1 part diet powder and 4 parts of a hot agar solution $(10 \mathrm{~g} / \mathrm{L})$. When diet supplemented with chemicals was prepared, the compounds were dissolved in the agar solution before the diet powder was added. Supplemented diets were always prepared fresh immediately before the experiment and the temperature stability of additives (e.g. tremulacin) was first verified.

Populus tremula $\mathrm{x}$ tremuloides foliage used in our experiments originated from clonal trees of line INRA 353-38 grown in a greenhouse under conditions as previously described (Boeckler et al., 2014). For the experiments with $P$. tremula $x$ tremuloides we always used leaves of comparably aged mature leaves.

\subsection{Collection of feces for salicinoid metabolite identification}

Feces extracts of gypsy moth caterpillars reared on an artificial diet devoid of salicinoids were compared to the feces extracts of individuals reared on the same diet supplemented with salicinoids (salicin, salicortin or tremulacin) or salicinoid metabolites (salicyl alcohol, catechol or benzoic acid). The compounds were either purified from $P$. tremula $\mathrm{x}$ tremuloides leaf material (salicortin and tremulacin) by semi-preparative HPLC as described previously (Boeckler et al., 2013) or purchased from Sigma-Aldrich (Taufkirchen, Germany, all other compounds). Each compound was added at a concentration of $38 \mu \mathrm{mol} / \mathrm{g}$ diet DW, which is at the lower end of the natural concentration range in poplar foliage. The diet containing each compound was apportioned into five $90 \mathrm{~mm}$ diameter Petri dishes $(\mathrm{n}=5)$ and three gypsy moth caterpillars previously starved for $24 \mathrm{~h}$ were added to each Petri dish. The caterpillars were allowed to feed for $5.5 \mathrm{~h}$ before they were transferred to a second Petri dish without diet for another 18 hours. The feces excreted within this $18 \mathrm{~h}$ period were then combined, flash frozen, lyophilized and then stored at $-20^{\circ} \mathrm{C}$ until extraction and LC-MS (ion trap) analysis. 
To test if the degradation of salicinoids in Lymantria dispar depended on previous salicinoid feeding experience, caterpillars hatched from a single egg batch were split in two groups after rearing on artificial diet to $4^{\text {th }}-5^{\text {th }}$ instar. The first group was transferred to poplar foliage ("experienced" caterpillars) while the second group remained on artificial diet ("naïve" caterpillars). The large amounts of poplar foliage required for rearing the "experienced caterpillars" in this experiment, were obtained from a mature P. nigra tree in Jena, Germany $\left(50^{\circ} 54^{\prime} 38.64 " \mathrm{~N}, 11^{\circ} 34^{\prime} 14.38^{\prime \prime} \mathrm{E}\right)$ with a known salicinoid profile (Boeckler et al., 2013).

After a 4 day feeding period the caterpillars of both groups were starved for $24 \mathrm{~h}$ and introduced into the actual experiment. Seven "experienced" and seven "naïve" caterpillars were immediately dissected to assess initial salicinoid metabolite levels. The remaining caterpillars of both groups were placed individually in containers and offered a $P$. tremula $\mathrm{x}$ tremuloides leaf disc $(\varnothing 24 \mathrm{~mm})$ for a period of $90 \mathrm{~min}$. Individuals that ate more than $30 \%$ of the leaf disc were then allowed to either digest for 90 min only or left for $24 \mathrm{~h}$ without provision of additional food. Twenty caterpillars of each treatment were removed for dissection after: $3 \mathrm{~h}(90 \mathrm{~min}$ feeding +90 min digestion) and after $24 \mathrm{~h}$ (90 min feeding $+22.5 \mathrm{~h}$ digestion). A $90 \mathrm{~min}$ interval after feeding was chosen to allow initial metabolism to take place. The $24 \mathrm{~h}$ time point was chosen because this time was observed to be sufficient for the passage of food through $4^{\text {th }}$ $5^{\text {th }}$ instar gypsy moth caterpillars and we wanted to learn if all salicinoid metabolites were also eliminated within this time. For dissection, the caterpillars were kept in plastic cups on ice, anesthetized with $\mathrm{CO}_{2}$ and then 2-3 midabdominal prolegs were removed to collect 20-100 $\mu \mathrm{L}$ hemolymph with a $200 \mu \mathrm{L}$ pipette. Then, the head was removed and the following dissection steps were carried out in a Petri dish filled with distilled water. 1. The integument was opened by a ventral longitudinal incision to expose the digestive system. 2 . The main gut was dissected and the Malpighian tubules were removed. 3. The readily distinguishable hind gut was separated from the midgut and foregut (designated together as the "main gut"). 4 . The fat body and integument were discarded as they were not suitable for chemical analysis with the extraction solvent employed due to emulsion formation. 5. Each organ was thoroughly washed with distilled water, weighed and transferred to liquid nitrogen immediately. Samples were stored at $-80^{\circ} \mathrm{C}$ until freeze-drying and dry weight recording. The extraction and analysis of salicinoid metabolites by LC-MS/MS is described below. Differences in metabolite concentrations between the two treatments and between the dissection time points were compared using a general least square (GLS) model. As a first step, we tested if the variance structure was best explained by dietary experience, dissection time or the interaction of both. 
127 The best structure was then used in a backward model reduction approach to test the significance of dietary experience, dissection time and their interaction.

\subsection{Efficiency of salicinoid conversion to identified metabolites}

131

In this experiment the recovery of salicinoid metabolites was determined in caterpillars with and without feeding experience on salicinoid-containing diet. L. dispar caterpillars reared on artificial diet to $4^{\text {th }}-5^{\text {th }}$ instar were split into two groups: one group ("naïve caterpillars") remained on artificial diet for four more days; the other group ("experienced" caterpillars) was offered poplar leaves for four days. The larvae of both groups were then starved for $48 \mathrm{~h}$, a time period chosen to minimize the occurrence of residual metabolites from previous feeding bouts. Sixty caterpillars of each group where then placed individually in Petri dishes containing a moist filter paper and offered a $30 \mathrm{~mm}$ P. tremula $\mathrm{x}$ tremuloides leaf disc for $2 \mathrm{~h}$. Leaf disc fresh weight was determined prior to placement in the Petri dishes. A subset of 20 caterpillars of both treatments that had consumed more than $20 \%$ of their leaf disc was then selected while the other 40 individuals were discarded. The remnants of each leaf disc were immediately weighed, and then flash-frozen and freeze-dried; after reweighing, the leaves were ground to a fine powder. The selected caterpillars were allowed to excrete feces for the following $48 \mathrm{~h}$, which were collected, freeze-dried and weighed. Salicinoids in the leaf discs were quantified by HPLC-UV and salicinoid metabolites in the feces were quantified by LC-MS/MS as described below. Foliar salicinoid concentrations were converted to a FW basis using the water content of the leaf disc remnants and this was used to calculate the amount of salicinoids ingested. Preliminary experiments had shown that neither salicinoid concentrations nor water content were significantly influenced by the $1.5 \mathrm{~h}$ feeding period (data not shown). The molar amount of excreted metabolites was calculated from their concentrations in the feces and the feces dry weight. The recovery rate of each metabolite in the feces was expressed as a percentage of the molar amount salicinoid precursor moiety ingested. Comparison between treatments was carried out after arcsine transformation using a parametric (t-test) or nonparametric test (Wilcoxon-test) depending on variance homogeneity and normal distribution.

\subsection{Effect of salicinoid metabolites on caterpillar performance}

Two week-old caterpillars in third instar were reared on artificial diet spiked with the salicinoid metabolites, salicin, catechol, benzoic acid or a mixture of the three, and compared to a control diet without additives. Concentrations $(200 \mu \mathrm{mol} / \mathrm{g}$ salicin, $150 \mu \mathrm{mol} / \mathrm{g}$ catechol and $50 \mu \mathrm{mol} / \mathrm{g}$ 
benzoic acid) were selected according to natural salicinoid concentrations of Populus tremula $\mathrm{x}$ tremuloides (Boeckler et al., 2014) assuming a quantitative release of metabolites from their respective salicinoid precursors. Ten Petri dishes of each diet were offered to groups of 7 caterpillars per dish. As we occasionally observed cannibalism during the first few days, we altered the experimental setup after three days. The number of caterpillars per dish was reduced to four and home-made plastic dividers were inserted in each of the experimental Petri dishes to ensure caterpillar separation. Every third day insects were transferred to freshly made diet with the same additives and caterpillar weight and mortality was recorded. The experiment was terminated after 15 days. Weight gain was compared using linear mixed effects models (lme). Although data were log-log transformed, the exponential growth curve of the caterpillars did not permit an analysis over the whole period of the experiment due to the inhomogeneity of variances. Therefore the comparison was restricted to data recorded between day 6 and day 15 . Transformed caterpillar weights were nested within Petri dishes, and treatment and recording day (as factors) entered the model successively as fixed effects and were tested against the null model. In order to compare the treatments, they were successively combined until the minimal adequate model was achieved. Caterpillar survival was tested by a Kaplan-Meier survival analysis using the optimal error distribution ("loggaussian").

\subsection{Salicinoid conjugates in other poplar herbivore species}

Eleven other poplar herbivores (Table 1) were either collected from black poplar (P. nigra) trees growing in a natural floodplain forest at Küstrin-Kietz, Germany (Boeckler et al., 2013) or kindly provided by hobby entomologists. All species were reared on P. nigra foliage and the feces of at least three individuals were collected. Feces were collected and stored at $-20^{\circ} \mathrm{C}$ until extraction. Depending on the sample mass, feces were extracted once with $200-1000 \mu \mathrm{L}$ aqueous $\mathrm{MeOH}(50 \% \mathrm{v}: \mathrm{v})$ and qualitatively analyzed for salicinoid metabolites by LC-MS (ion-trap) and LC/MS/MS using the methods described below.

\subsection{LC/MS (ion trap) analysis of salicinoids and salicinoid metabolites}

Feces extracts were analyzed on an Agilent 1100 series chromatograph equipped with a reversed phase column (EC 250/4.6 Nucleodur Sphinx, RP $5 \mu \mathrm{m}$, Macherey-Nagel, Düren, Germany) at $25{ }^{\circ} \mathrm{C}$ and $0.2 \%$ formic acid and acetonitrile as solvents $\mathrm{A}$ and $\mathrm{B}$, respectively. Gradient elution with the following parameters was applied: 0-100 \% B (0-50 min), $100 \%$ B (50-55 min), 0 \% B (55-60 min). After chromatographic separation, analytes where detected using an Esquire 6000 ESI-ion trap mass spectrometer (Bruker Daltonics, Bremen, Germany) 
operated in alternating ionization mode and scanning a mass range from $m / z=60-1200$. Nitrogen served as nebulizer (35 psi) and drying gas $\left(11 \mathrm{l} / \mathrm{min}, 330{ }^{\circ} \mathrm{C}\right)$. MS chromatograms of different diets were compared using the MetaboliteDetect 1.1 software provided by Bruker Daltonics (Bremen, Germany). This software subtracts a reference chromatogram (e.g. control diet) from a given chromatogram (e.g. salicin diet) and was set to calculate a differential chromatogram showing only $\mathrm{m} / \mathrm{z}$ that had a two times higher intensity than in the reference chromatogram. Salicinoids and most of their metabolites were readily detected in the negative mode which was also applied for MSn experiments using the Auto-MS function of the Esquire control software.

\subsection{Quantitative analysis of salicinoids by HPLC-UV}

Foliar salicinoid levels were determined as described (Boeckler et al., 2013). Briefly, a 5 mg portion of leaf powder was extracted twice with $1 \mathrm{ml} \mathrm{MeOH}$. In the first extraction step, $0.8 \mathrm{mg}$ phenyl- $\beta$-glucopyranoside was added as an internal standard. Combined extracts were analyzed by HPLC as described previously and salicinoids were quantified with aid of calibration curves.

For quantitative analysis of salicinoid metabolites by LC-MS/MS, caterpillar tissues and feces were extracted whole without further treatment using $50 \%$ aqueous $\mathrm{MeOH}$ containing $5 \mu \mathrm{g} / \mathrm{ml}$ arbutin as internal standard. Feces and main guts were extracted twice with $750 \mu \mathrm{L}$. Hemolymph, Malpighian tubules and hind guts had low samples masses (below $1 \mathrm{mg}$ ) and were only extracted once with $200 \mu \mathrm{L}$ to avoid trace analyte dilution. Each extraction step started with 5 min ultrasonication followed by 4 min of agitation on a paint shaker. Insoluble residue was spun down and the supernatant was used for chemical analysis. If necessary, the extracts were diluted 1:100 or 1:1000 with the extraction solvent to ensure that responses of abundant metabolites were within the calibration range.

Analytes were chromatographed on an Agilent 1200 series HPLC system equipped with an Agilent XDB-C-18 column (4.6 x $50 \mathrm{~mm}, 1.8 \mu \mathrm{m})$. Gradient elution with $0.05 \%$ aqueous formic acid (A) and acetonitrile (B) was applied using the following parameters: $5 \% \mathrm{~B}(0-0.5$ $\min ), 5-70 \% \mathrm{~B}$ (0.5-4.5 min), 70-100 \% B (4.5-6 min), $100 \% \mathrm{~B}(6.0-6.5 \mathrm{~min}), 5 \% \mathrm{~B}(6.5-10$ min). Eluted compounds were ionized by electrospray (negative mode) and detected on an API 5000 LC/MS/MS mass spectrometer (Applied Biosystems, Carlsbad, CA, USA) using multiple reaction monitoring (MRM). MRM parameters for each analyte were optimized using standard compounds, either purchased or isolated from caterpillar feces as described below under "Isolation and identification of unknown salicinoid metabolites". These standards were also 
238

used to generate standard curves referenced to the internal standard arbutin. Concentrations were determined using average response factors calculated from data points within the linear range of the standard curves. In undiluted extracts, the internal standard was subject to apparent ion suppression due to its co-elution with other sugar conjugates. Thus quantification by external standard curves was carried out. MRM-parameters: (precursor ion $\mathrm{m} / \mathrm{z} \rightarrow$ product ion $m / z$; declustering potential [V], collision energy [V]): catechol $(109 \rightarrow 91 ;-30,-24)$, catechol glucoside $(270 \rightarrow 109 ;-25,-24)$ catechol glucoside phosphate $(351 \rightarrow 79 ;-30,-52)$, salicin $(285 \rightarrow 123 ;-30,-18)$, salicin phosphate $(365 \rightarrow 79 ;-30,-52)$, hippuric acid $(178 \rightarrow 134 ;-20,-$ 13), salicortin $(423 \rightarrow 123 ;-55,-30)$, tremuloidin $(389 \rightarrow 121 ;-20,-26)$, tremulacin $(527 \rightarrow 123 ;-$ $55,-34)$, arbutin $(271 \rightarrow 161 ;-20,-16)$.

\subsection{Isolation and identification of unknown salicinoid metabolites}

Two metabolites, salicin phosphate and catechol glucoside phosphate, reported here for the first time, were isolated from the feces in bulk for structure elucidation. Several grams of feces containing these two metabolites were acquired by feeding $4-5^{\text {th }}$ instar caterpillars with salicin (10 \% DW) or catechol (1 \% DW) supplemented diet. LC/MS analysis had indicated that caterpillars produced catechol glucoside phosphate (and catechol glucoside) from both salicinoids containing the HCC moiety and from catechol. Both phosphates were purified using the same protocol but were isolated separately. Approximately $1 \mathrm{~g}$ of feces was extracted three times with $5 \mathrm{ml} 0.1$ molar aqueous $\mathrm{NH}_{3}$. The extract was applied to a $500 \mathrm{mg}$ Chromabond HR-XA SPE column which was subsequently washed with $5 \mathrm{ml}$ water and $5 \mathrm{ml} \mathrm{MeOH}$. Residual washing solvent was removed by aspiration and compounds were eluted three times with $1 \mathrm{ml}$ of a $1 \mathrm{M}$ ammonia formate solution in $\mathrm{MeOH}$. The eluate was fractionated on a reversed phase column (EC 250/4.6 Nucleodur Sphinx, RP $5 \mu \mathrm{m}$, Macherey-Nagel, Düren, Germany) using a gradient of 20 mmolar ammonium acetate and acetonitrile (ACN) at 1 $\mathrm{ml} / \mathrm{min}$. The ACN proportion was increased from $0 \%$ to $10 \%$ within $10 \mathrm{~min}$, followed by a 3 min wash with $100 \% \mathrm{ACN}$ and a 3 min re-equilibration to $0 \% \mathrm{ACN}$. Salicin phosphate and catechol glucoside fractions were collected from 8:48-9:12 and 9:12-9:22 min, respectively. The solvent was removed using a rotary evaporator and the solid residue was dissolved in a small portion of $\mathrm{MeOH}$. This solution was again fractionated on a reversed phased column (Supelcosil LC-18-DB semi-prep, $25 \mathrm{~cm}$ x $10 \mathrm{~mm}$ x $5 \mu \mathrm{m}$ ) eluted with $10 \mathrm{mmol}$ ammonium acetate (adjusted to $\mathrm{pH} 4$ with acetic acid) and ACN. The initial proportion of $5 \%$ ACN was increased to $17 \%$ within $6 \mathrm{~min}$, followed by a 2 min wash with $100 \% \mathrm{ACN}$ and a two min re- 
equilibration with $5 \%$ ACN. Salicin phosphate and catechol glucoside phosphate were both collected from 4:06-4:48 $\mathrm{min}$. The solvent was evaporated to yield approximately $0.5 \mathrm{mg}$ of the respective phosphate, which was analyzed by MS (Suppl. File 1) and NMR (Suppl. File 2).

A third unknown metabolite, the catechol $\mathrm{N}$-acetylcysteine adduct was generated in vitro as part of preliminary experiments to test the reactivity of catechol. The compound was then detected in L. dispar feces, and its structure proven by synthesis and comparison of spectra with those of the authentic compound (Suppl. File 3).

\subsection{Statistical analysis}

270 We used the open access software package R 2.15.0 for all statistical tests. The statistical 271 assumptions such as normal distribution and heteroscedasticity were always checked. Percent 272 data (recovery rates) were arcsine transformed prior to statistical analysis. 


\section{$274 \quad 3.1$ Identification of salicinoid metabolites in caterpillar feces}

275 Altogether seven salicinoid metabolites were identified in the feces of $L$. dispar caterpillars fed salicin, salicortin and tremulacin in artificial diets at natural concentrations (Fig. 1). Three of these compounds, salicin phosphate (salicyl- $\beta$-D-glucoside-3-phosphate), catechol glucoside phosphate (catecholyl- $\beta$-D-glucoside-3-phosphate) and the catechol $\mathrm{N}$-acetylcysteine adduct, had not been previously reported. Compounds were identified based on mass spectrometry fragmentation patterns (Suppl. File 1) and NMR spectroscopy (Suppl. File 2, 3) and, for known compounds, in comparison to data of commercial standards.

The modular composition of salicinoids allowed the seven metabolites to be traced back to specific elements in their structures (Fig. 1). For example, the catechol-type metabolites were only observed when the diet contained salicortin or tremulacin, and therefore must derive from the hydroxyl cyclohexanone carboxylic acid ester (HCC) moiety that occurs only in salicortin and tremulacin, and not salicin. Hippuric acid occurred only when the caterpillars had fed on tremulacin, and thus it is most likely derived from the benzoyl ester moiety exclusive to this salicinoid. Saligenin, salicin and salicin phosphate were not specific to a single salicinoid, and consequently originate from the salicin core structure characteristic of each of these compounds.

\subsection{In-vivo distribution and kinetics of salicinoid metabolism in caterpillars}

To determine the kinetics of salicinoid metabolism in L. dispar, various tissues were analyzed before and after $90 \mathrm{~min}$ and $24 \mathrm{~h}$, respectively, of feeding on poplar (Populus tremula $\mathrm{x}$ tremuloides) which contains the salicinoids salicin, salicortin and tremulacin (Boeckler et al., 2014). The metabolites identified were generally detectable in all tissues analyzed, including the main gut, hemolymph, Malpighian tubules and hindgut (Fig. 2). Prior to the feeding bout, none of the compounds (except the catechol $\mathrm{N}$-acetylcysteine adduct) was detected in caterpillars that had not previously fed on poplar. Substantial amounts of the metabolites were detected 3 hours after feeding started, but these generally declined by 24 hours ( $\mathrm{P}<0.001$, Fig. 2). However, catechol glucoside phosphate and salicin phosphate levels remained elevated in the hemolymph and hippuric acid remained elevated in all tissues.

The metabolism of caterpillars that had been raised on poplar was compared to caterpillars raised on an artificial diet. At the $3 \mathrm{~h}$ measurements, caterpillars with poplar-feeding experience contained more catechol glucoside, salicin and hippuric acid than caterpillars fed on 
artificial diets, while catechol glucoside phosphate and salicin phosphate were typically higher in those fed on artificial diets (Fig. 2).

\subsection{Efficiency of conversion of parent salicinoids to identified metabolites}

The extent of breakdown of the parent salicinoids in the plant to the identified metabolites was assessed by comparing the amounts of each of the major salicinoid moieties in poplar foliage with the amounts of metabolites in gypsy moth feces. The initial foliage consisted of Populus tremula $\mathrm{x}$ tremuloides leaf discs containing $16.8 \pm 2.1 \mu \mathrm{mol} / \mathrm{g}$ salicin, $104.4 \pm 3.5 \mu \mathrm{mol} / \mathrm{g}$ salicortin (salicin and HCC moieties) and $42.4 \pm 2.1 \mu \mathrm{mol} / \mathrm{g}$ tremulacin (salicin, HCC and benzoyl moieties).

The gypsy moth feces contained no salicortin or tremulacin, but did contain salicin which may arise from the breakdown of salicortin and tremulacin to salicin or from unreacted salicin. The products of salicin metabolism, including saligenin, salicin phosphate and salicin, accounted for nearly the full amount of the salicin moiety ingested for caterpillars that had experience on poplar foliage, but accounted for only $50 \%$ of the ingested salicin moiety for caterpillars fed on artificial diet. In contrast, the recovery rate of metabolites from the HCC moiety (found in both salicortin and tremulacin) was much lower for both poplar- and artificial diet-fed caterpillars. Poplar-fed caterpillars excreted over twice as much catechol glucoside (P $<0.001)$ as artificial diet-fed caterpillars, but only half as much catechol glucoside phosphate $(\mathrm{P}<0.001$, Fig. 3).

The metabolite hippuric acid represents the benzoyl moiety of tremulacin, and accounted for $80 \%$ and $120 \%$ of the ingested benzoyl moieties in artificial diet-fed and poplarfed caterpillars, respectively. The excess of hippuric acid in the poplar-fed caterpillars and the detection of this metabolite after ingestion of foliage from deciduous tree species without salicinoids (Suppl. Fig. 4) suggest that hippuric acid can arise not only from salicinoids like tremulacin, but also from other substances. When salicin- and HCC-derived metabolites were combined, the proportion of phosphorylated compounds was lower in the poplar-fed caterpillars (42\%) as compared to the artificial diet-fed caterpillars (63\%).

\subsection{Effect of salicinoid metabolites on caterpillar performance}


336 To determine the toxicity of various salicinoid degradation products and metabolites to $L$.

337 dispar, these were added to an artificial diet, and their effect on larval performance was

338 determined. Caterpillar weight gain on the benzoic acid and control diets was comparable and

339 higher than weight gain on the other three treatments. On the salicin and catechol diets, weight

340 gain was intermediate differing significantly from all the other treatments, but not from each

341 other. Finally, caterpillars feeding on a mixed diet consisting of salicin, catechol and benzoic

342 acid weighed significantly less than those on any other treatment (Fig. 4, $\mathrm{P}<0.001$ ).

343 Caterpillar survival (excluding cannibalism) was also significantly lower on the mixed diet,

344 while it did not differ between any of the other four treatments (Fig. 4, p<0.001).

345

$346 \quad 3.5$ Salicinoid metabolites in other insect herbivores

347 The feces of 11 other poplar herbivores were analyzed after being fed on poplar foliage to

348 assess if the salicinoid processing reactions found in $L$. dispar caterpillars are widespread. The 349 feces of all tested lepidopterans but not the beetle Chrysomela populi contained salicin. In 350 contrast, salicin phosphate and catechol glucoside phosphate were only present in the feces of 351 Orgyia antiqua, a close relative of $L$. dispar. The catechol $\mathrm{N}$-acetylcysteine adduct was excreted only by Cerura vinula and Selenia dentaria.

353 To determine if other simple phenolic glycosides can be phosphorylated, L. dispar 354 caterpillars were fed with arbutin (hydroquinone O-glucoside) and helicin (the O-glucoside of 355 salicylaldehyde). Both compounds were phosphorylated on their glucose residues, while 356 administration of phenol gave both the corresponding glucoside and the phosphorylated 357 glucoside (Suppl. Fig. 5). 
4.1 Salicinoid degradation in gypsy moth caterpillars involves initial ester cleavage and formation of toxic products

Salicinoids are plant anti-herbivore defenses that are thought to be activated and transformed into toxic derivatives upon plant damage or inside the herbivore (reviewed in Boeckler et al., 2011). Other types of activated defenses are known in plants, and these are typically glycosides do contain a $\beta$-glucoside moiety, but it is unclear if activation arises from glucose hydrolysis or from hydrolysis of ester linkages. All salicinoids except salicin contain ester bonds linking organic acids to various hydroxyl groups of the salicin core structure (Fig. 1).

In our investigations of salicinoid metabolism in gypsy moth caterpillars (Lymantria dispar), we fed foliage or artificial diet containing two compounds with such ester linkages, salicortin and tremulacin, and found no metabolites with intact ester bonds. Ester degradation is likely driven by the alkaline gut conditions found in $L$. dispar and other lepidopterans (Johnson and Felton, 1996; Ruuhola et al., 2001). A basic pH in the guts of herbivorous insects is believed to suppress plant glucosidases and avoid the bioactivation of glucosidic plant defenses (Pentzold et al., 2014), and may help to minimize astringency caused by tannins (reviewed by Barbehenn and Constabel, 2011; Berebaum, 1980), but favors spontaneous (nonenzymatic) degradation of ester bonds. Ester hydrolysis of salicortin yields salicin and hydroxycyclohexanone carboxylic acid (HCC), while hydrolysis of tremulacin yields salicin, HCC and benzoic acid (Fig. 1).

HCC is subject to further conversions in L. dispar as indicated by the catechol derivatives found in the feces only when salicinoids with the HCC moiety are fed upon. Previous studies provided evidence for HCC conversion to catechol after spontaneous decarboxylation and oxidation (Clausen et al., 1989). Support for alternative conversions of HCC (Clausen et al., 1990; Julkunen-Tiitto and Meier, 1992) was not obtained in the current work.

Given the formation of salicin, catechol and benzoic acid in L. dispar guts after ester hydrolysis, we investigated their toxicity to gypsy moth larvae in a longer-term experiment when fed at concentrations approximating those likely to be present in the insect after ingesting P. tremula $\mathrm{x}$ tremuloides foliage assuming complete conversion of salicinoids to these metabolites. While benzoic acid was not toxic to the gypsy moth, salicin and catechol both inhibited growth significantly. In earlier studies salicin was observed to have little if any antiherbivore activity (Lindroth, 1988; Lindroth and Peterson, 1988), possibly because it was fed at 
doses matching the low foliage concentration rather than at higher doses taking into account the salicin formed from degradation of other salicinoids, as done here.

It is currently unclear how salicin or its aglycone saligenin could act on herbivores. Saligenin could serve as an uncoupler of cell respiration, as was shown by the carboxylated analog salicylic acid (Terada, 1990). The toxicity of catechol is likely due to oxidation to quinones (Appel, 1993; Pourcel et al., 2007), which are potent electrophiles (Bittner, 2006) and can crosslink amino acids, as is the case during food browning (Friedman, 1996). In fact, the feces of L. dispar fed catechol containing artificial had a darker color compared to control feces, indicating that quinone-driven reactions may have occurred. In contrast to their effects on L. dispar growth, salicin and catechol had no effect on caterpillar survival, but a mixture of these compounds with benzoic acid caused a significant increase in mortality, indicating synergistic negative effects. In how far salicin cleavage, catechol oxidation or potential other activation reactions are driven by plant endogenous enzymes is not verifiable by our results. However, metabolite profiles in the feces of caterpillars fed poplar leaves or artificial diet devoid of plant enzymes were rather similar. Therefore the metabolic routes suggested above likely involve spontaneous reactions or are catalyzed by digestive enzymes originating from the caterpillars, but an additional role of plant enzymes is still possible.

\subsection{Most identified salicinoid metabolites are products of phase II conjugation reactions}

The majority of the salicinoid metabolites identified in $L$. dispar feces are formed by conjugation with glucose (catechol glucoside), phosphate (salicin phosphate, catechol glucoside phosphate) or amino acids and derivatives (hippuric acid, N-acetylcysteine catechol adduct). These are typical products of phase II detoxification reactions that increase polarity and facilitate excretion. While glucose (Ahmad and Hopkins, 1993; Ahn et al., 2011; Luque et al., 2002; Sasai et al., 2009; Wouters et al., 2014) and amino acid (Konno et al., 1996; Nijhout, 1975; Novoselov et al., 2015; Stauber et al., 2012) conjugates are well known in insects, phosphate metabolites of plant defenses are without precedent.

Given the critical metabolic roles of phosphorus in insects and literature reports that phosphorus deficiency limits insect growth (Elser et al., 2007; Visanuvimol and Bertram, 2011), it is not clear why insects would synthesize phosphate conjugates in metabolism of host plant defenses. Among the possibilities, 1) phosphorylation could serve as a metabolic tag that marks certain glycosides for efflux processes by phosphate specific transporters, an effective way of eliminating glycosides from the hemolymph against a concentration gradient. 2) Phosphorylation could avoid re-activation of glycosidic conjugates by glucosidases. Sugar 
426 phosphorylation has a substantial impact on steric properties and polarity, and may prevent glucosidase action. 3) The excretion of excess phosphorus in the form of phosphates could be a strategy of insect herbivores to reach an optimal phosphate level in relation to other nutrients. For example, tight maintenance of phosphate homeostasis has been observed in the grasshopper Oedaleus asiaticus (Zhang et al., 2014). The amount of phosphorus used in producing salicinoid metabolites makes up a substantial portion of the overall phosphorus budget of $L$. dispar. P. nigra foliage contains an average of $100 \mu \mathrm{mol} / \mathrm{g}$ phosphorus-, while salicin phosphate and catechol glucoside phosphate in the feces of $L$. dispar caterpillars fed $P$. tremula $\mathrm{x}$ tremuloides add up to approximately $50 \mu \mathrm{mol} / \mathrm{g}$ (Boeckler, unpublished results). Assuming that poplar foliage has an approximate digestibility of 0.5 based on dry weight (Kinney et al., 1997), our results suggest that under natural conditions gypsy moth larvae expend up to one quarter of their phosphorus uptake on salicinoid detoxification. While the amount of phosphorus in the artificial diet may have been higher than that in P. tremula $\mathrm{x}$ tremuloides foliage, the overall amounts of phosphorylated metabolites formed in L. dispar larvae feeding on artificial diet were not greater than those formed in foliage-fed larvae. Only the relative abundance of the two phosphorylated products was altered. L. dispar was able to phosphorylate other phenolic glycosides and phenol offered in artificial diet (Suppl. File 5), suggesting that the ability to produce phosphate conjugates of phenolic compounds may be a general response in this and perhaps other insect species.

Among the amino acid conjugates found in this study, the glycine conjugate of benzoic acid (hippuric acid) reported here has long been known from other insects (Nijhout, 1975; Shyamala, 1964), and it has been speculated that some Lepidopteran species maintain high concentrations of glycine in their guts to detoxify dietary aromatic acids (Konno et al., 1996). The N-acetylcysteine conjugate of catechol has not been previously reported in insects, and probably arises via initial conjugation with glutathione followed by peptidase cleavage of the $\gamma$-glutamate and glycine residues of glutathione and subsequent $\mathrm{N}$-acetylation, along the socalled mercapturic acid pathway, as described in other insects (Gloss et al., 2014) and mammals (Cristofori et al., 2015). The conjugation of glutathione with another group of plant defense compounds, the isothiocyanates, is well known (Gloss et al., 2014; Schramm et al., 2012).

Our work on gypsy moth metabolism of salicinoids is one of the first to report on phenolic processing in a generalist insect herbivore. To determine if the seven salicinoid metabolites formed by gypsy moth are also produced in other insect herbivores, we analyzed the feces of 11 other insect herbivores, 10 lepidopterans and one coleopteran, after feeding on 
poplar. All of the metabolites identified here, except for the phosphates, were detected in all species (Table 1), but the phosphates were only present in the feces of the rusty tussock moth (Orgyia antigua), a close relative of Lymantria dispar.

\subsection{Localization and transport of salicinoid metabolites in gypsy moth}

Our results on the distribution of salicinoid metabolites in various organs of gypsy moth larvae shed light on the localization of the metabolite-forming reactions and subsequent transport processes. After initial ester cleavage of salicinoids in the gut lumen, the phase II conjugation reactions must take place within cells because these reactions require intracellular enzymes and high energy cellular intermediates, such as UDPG and glutathione, and would not be favored under the typical $\mathrm{pH}$ environment of the insect gut. The probable location is the epithelial cells lining the gut lumen, site of many metabolic reactions associated with nutrient digestion, assimilation and detoxification (Appel and Martin, 1990; Novoselov et al., 2015). After conjugation, the polar products can be transported back into the gut lumen for excretion or loaded in the hemolymph. The release of conjugates in the gut lumen reduces their proximity to internal metabolism, but hemolymph loading may prevent reaction by digestive enzymes. Both processes appear to occur in L. dispar since both gut tissue and hemolymph contained substantial amounts of salicinoid metabolites (Fig. 2). In insects, the elimination of waste products from the hemolymph is carried out by the Malpighian tubules (Chahine and O'Donnell, 2011), but so far there is little direct evidence for the function of these organs in plant defense detoxification. In the gypsy moth, most salicinoid conjugates were concentrated at higher levels in the Malpighian tubules as compared to the hemolymph (Fig. 2), indicating that these organs have a major responsibility for translocation to the hindgut, in which even higher concentrations of conjugates were observed. Deposition in the hindgut was followed finally by elimination in the feces. Whatever the route to the hindgut, $L$. dispar caterpillars metabolized salicinoids and eliminated most of the identified metabolites in less than 24 hours. Alternatively, salicinoid metabolism may be carried out within the cells of endosymbiotic microbes, which could play an important role in detoxification of plant defenses in insects (Engel and Moran, 2013). In L. dispar, Acinetobacter species derived from the host plant have been demonstrated to metabolize salicinoids (Mason et al., 2014; Mason et al., 2015).

Insect metabolism of plant defenses is not a static process, but is conditioned by initial exposure to a compound such that metabolism is elevated upon subsequent contact (Dugravot et al., 2004; Falk and Gershenzon, 2007; Li et al., 2004; Zhang et al., 2012). Such flexibility is considered an adaptive mechanism for reducing metabolic costs in generalist herbivores, such 
494 as gypsy moth caterpillars, that often switch host plants during larval development. In this 495 study, most salicinoid metabolites were formed at higher levels in larvae that had prior 496 experience with poplar foliage compared to larvae that had fed only on artificial diet (Fig. 3).

497 Elimination rates were also affected by feeding experience. Of the compounds remaining at 498 high levels in the hemolymph after $3 \mathrm{~h}$, salicin phosphate and catechol glucoside phosphate 499 were three times less abundant in larvae that had fed on poplar suggesting a much higher 500 elimination rate in experienced insects. Poplar-experienced caterpillars also eliminated salicin 501 more efficiently than caterpillars fed on artificial diet, although the recovery of the HCC 502 moiety was similar. For both the salicin and HCC moieties, recovery was sometimes low, less 503 than $50 \%$ and $30 \%$, respectively, depending on treatment. Hence there must be other metabolic 504 sinks in L. dispar caterpillars than the observed conjugates. Rats have been reported to oxidize 505 salicin (Akao et al., 2002) and specialized leaf beetles convert this compound to 506 salicylaldehyde (Strauss et al., 2013), which they use to deter predators. For HCC, two 507 metabolic routes have been suggested in the literature, which both involve irreversible covalent 508 binding to proteins. Clausen et al (1990) found that HCC can form quinone methides which 509 attack and deactivate glucosidases (Zhu et al., 1998). Alternatively, if catechol is derived from 510 the HCC moiety, as shown in our work and previously (Pearl and Darling, 1970; Ruuhola et 511 al., 2003), this compound could also form quinones and react with proteins (Appel, 1993).

512 Further work is needed to document the metabolism of salicinoids in gypsy moth more 513 completely. The use of isotopically-labeled precursors might facilitate the identification of the 514 remaining major metabolites, as well as make progress in deducing the mode of action of 515 salicinoids in herbivores like the gypsy moth. Little is known about the molecular targets of 516 salicinoids and other plant phenolic defense compounds in insect herbivores. Once the 517 principal pathways of salicinoid processing are elucidated, researchers can turn to identifying 518 the genes and enzymes involved. Characterization of the properties of these genes and enzymes 519 and their evolutionary origin should give many new insights into plant-herbivore interactions 520 occurring in a whole range of poplars, willows and other plants that produce phenolics. 


\section{Acknowledgements}

522 We thank Peter Constabel for donating the P. tremula $\mathrm{x}$ tremuloides trees, Bernd Schneider for 523 providing phenolic standards, Beate Rothe, Michel Stelter, Elisabeth Fial, Christin Uhe, 524 Simone Frommeyer and Michael Reichelt for help in the lab. Furthermore we thank Otto Elias 525 and Hannah Nadel (USDA) for providing poplar insect herbivore species and the Max Planck 526 Society for funding. 
528 Abreu, I.N., Ahnlund, M., Moritz, T., Albrectsen, B.R., 2011. UHPLC-ESI/TOFMS 529 determination of salicylate-like phenolic gycosides in Populus tremula leaves. J. Chem. Ecol. $530 \quad 37,857-870$.

531 Ahmad, S.A., Hopkins, T.L., 1993. $\beta$-glucosylation of plant phenolics by phenol $\beta$ glucosyltransferase in larval tissues of the tobacco hornworm, Manduca sexta (L.). Insect 533 Biochem. Mol. Biol. 23, 581-589.

534 Ahn, S.J., Badenes-Perez, F.R., Reichelt, M., Svatos, A., Schneider, B., Gershenzon, J., 535 Heckel, D.G., 2011. Metabolic detoxification of capsaicin by UDP-glycosyltransferase in three 536 Helicoverpa species. Arch. Insect Biochem. Physiol. 78, 104-118.

537 Ahn, S.J., Vogel, H., Heckel, D.G., 2012. Comparative analysis of the UDP538 glycosyltransferase multigene family in insects. Insect Biochem. Mol. Biol. 42, 133-147.

539 Akao, T., Yoshino, T., Kobashi, K., Hattori, M., 2002. Evaluation of salicin as an antipyretic 540 prodrug that does not cause gastric injury. Planta Med. 68, 714-718.

541 Appel, H.M., 1993. Phenolics in ecological interactions: the importance of oxidation. J. Chem. 542 Ecol. 19, 1521-1552.

543 Appel, H.M., Martin, M.M., 1990. Gut redox conditions in herbivorous lepidopteran larvae. J. 544 Chem. Ecol. 16, 3277-3290.

545 Barbehenn, R.V., Constabel, C.P., 2011. Tannins in plant-herbivore interactions. 546 Phytochemistry 72, 1551-1565.

547 Berenbaum, M., 1980. Adaptive significance of midgut PH in larval lepidoptera. Amer. Nat. $548 \quad 115,138-146$.

549 Bittner, S., 2006. When quinones meet amino acids: chemical, physical and biological 550 consequences. Amino Acids 30, 205-224.

551 Boeckler, G.A., Gershenzon, J., Unsicker, S.B., 2011. Phenolic glycosides of the Salicaceae 552 and their role as anti-herbivore defenses. Phytochemistry 72, 1497-1509.

553 Boeckler, G.A., Gershenzon, J., Unsicker, S.B., 2013. Gypsy moth caterpillar feeding has only 554 a marginal impact on phenolic compounds in old-growth black poplar. J. Chem. Ecol. 39, 555 1301-1312.

556 Boeckler, G.A., Towns, M., Unsicker, S.B., Mellway, R.D., Yip, L., Hilke, I., Gershenzon, J., 557 Constabel, C.P., 2014. Transgenic upregulation of the condensed tannin pathway in poplar 558 leads to a dramatic shift in leaf palatability for two tree-feeding Lepidoptera. J. Chem. Ecol. 40, 559 150-158. 
560 Chahine, S., O'Donnell, M.J., 2011. Interactions between detoxification mechanisms and excretion in Malpighian tubules of Drosophila melanogaster. J. Exp. Biol. 214, 462-468. Clausen, T.P., Keller, J.W., Reichardt, P.B., 1990. Aglycone fragmentation accompanies $\beta$ glucosidase catalyzed hydrolysis of salicortin, a naturally-occuring phenol glycoside. Tetrahedron Lett. 31, 4537-4538. model for short-term induction in quaking aspen (Populus tremuloides) foliage against herbivores. J. Chem. Ecol. 15, 2335-2346.

Cristofori, P., Sauer, A.V., Trevisan, A., 2015. Three common pathways of nephrotoxicity induced by halogenated alkenes. Cell Biol. Toxicol. 31, 1-13.

Després, L., David, J.P., Gallet, C., 2007. The evolutionary ecology of insect resistance to plant chemicals. Trends Ecol. Evol. 22, 298-307.

572 du Rand, E.E., Smit, S., Beukes, M., Apostolides, Z., Pirk, C.W.W., Nicolson, S.W., 2015. 573 Detoxification mechanisms of honey bees (Apis mellifera) resulting in tolerance of dietary $574 \quad$ nicotine. Sci. Rep. 5: 11779.

Dugravot, S., Thibout, E., Abo-Ghalia, A., Huignard, J., 2004. How a specialist and a nonspecialist insect cope with dimethyl disulfide produced by Allium porrum. Entomol. Exp. Appl. 113, 173-179.

Elser, J.J., Bracken, M.E.S., Cleland, E.E., Gruner, D.S., Harpole, W.S., Hillebrand, H., Ngai, J.T., Seabloom, E.W., Shurin, J.B., Smith, J.E., 2007. Global analysis of nitrogen and phosphorus limitation of primary producers in freshwater, marine and terrestrial ecosystems. Ecol. Lett. 10, 1135-1142.

Engel, P., Moran, N.A., 2013. The gut microbiota of insects - diversity in structure and function. FEMS Microbiol. Rev. 37, 699-735.

Falk, K.L., Gershenzon, J., 2007. The desert locust, Schistocerca gregaria, detoxifies the glucosinolates of Schouwia purpurea by desulfation. J. Chem. Ecol. 33, 1542-1555. Friedman, M., 1996. Food browning and its prevention: An overview. J. Agric. Food Chem. $58744,631-653$.

588 Giraudo, M., Hilliou, F., Fricaux, T., Audant, P., Feyereisen, R., Le Goff, G., 2015. Cytochrome P450s from the fall armyworm (Spodoptera frugiperda): responses to plant allelochemicals and pesticides. Insect Mol. Biol. 24, 115-128.

591 Gloss, A.D., Vassao, D.G., Hailey, A.L., Nelson Dittrich, A.C., Schramm, K., Reichelt, M., 592 Rast, T.J., Weichsel, A., Cravens, M.G., Gershenzon, J., Montfort, W.R., Whiteman, N.K., 
2014. Evolution in an ancient detoxification pathway is coupled with a transition to herbivory 594 in the Drosophilidae. Mol. Biol. Evol. 31, 2441-2456.

Heckel, D.G., 2014. Insect detoxification and sequestration strategies. Annu. Plant Rev. 47, 77114.

Heidel-Fischer, H.M., Vogel, H., 2015. Molecular mechanisms of insect adaptation to plant secondary compounds. Curr. Opin. Insect Sci. 8, 8-14.

599 Hemming, J.D.C., Lindroth, R.L., 1995. Intraspecific variation in aspen phytochemistry: 600 Effects on performance of gypsy moth and forest tent caterpillars. Oecologia 103, 79-88.

601 Johnson, K.S., Felton, G.W., 1996. Potential influence of midgut pH and redox potential on 602 protein utilization in insect herbivores. Arch. Insect Biochem. Physiol. 32, 85-105.

603 Julkunen-Tiitto, R., Meier, B., 1992. The enzymatic decomposition of salicin and its 604 derivatives obtained from Salicaceae species. J. Nat. Prod. 55, 1204-1212.

605 Kinney, K.K., Lindroth, R.L., Jung, S.M., Nordheim, E.V., 1997. Effects of CO2 and NO3606 availability on deciduous trees: Phytochemistry and insect performance. Ecology 78, 215-230.

607 Knuth, S., Abdelsalam, R.M., Khayyal, M.T., Schweda, F., Heilmann, J., Kees, M.G., Mair, 608 G., Kees, F., Jurgenliemk, G., 2013. Catechol conjugates are in vivo metabolites of Salicis 609 cortex. Planta Med. 79, 1489-1494.

610 Konno, K., Hirayama, C., Shinbo, H., 1996. Unusually high concentration of free glycine in the 611 midgut content of the silkworm, Bombyx mori, and other lepidopteran larvae. Comp. Biochem. 612 Physiol. A 115, 229-235.

613 Li, W., Zangerl, A.R., Schuler, M.A., Berenbaum, M.R., 2004. Characterization and evolution 614 of furanocoumarin-inducible cytochrome P450s in the parsnip webworm, Depressaria 615 pastinacella. Insect Mol. Biol. 13, 603-613.

616 Lindroth, R.L., 1988. Effects of quaking aspen compounds catechol, salicin and isoniazid on 2 617 subspecies of tiger swallowtails. Am. Midl. Nat. 119, 1-6.

618 Lindroth, R.L., 1991. Biochemical ecology of aspen-Lepidoptera interactions. J. Kansas 619 Entomol. Soc. 64, 372-380.

620 Lindroth, R.L., Peterson, S.S., 1988. Effects of plant phenols on performance of southern 621 armyworm larvae. Oecologia 75, 185-189.

622 Lu, F.G., Fu, K.Y., Li, Q., Guo, W.C., Ahmat, T., Li, G.Q., 2015. Identification of 623 carboxylesterase genes and their expression profiles in the Colorado potato beetle Leptinotarsa 624 decemlineata treated with fipronil and cyhalothrin. Pest. Biochem. Physiol. 122, 86-95.

625 Luque, T., Okano, K., O'Reilly, D.R., 2002. Characterization of a novel silkworm (Bombyx 626 mori) phenol UDP-glucosyltransferase. Eur. J. Biochem. 269, 819-825. 
627 Mason, C.J., Couture, J.J., Raffa, K.F., 2014. Plant-associated bacteria degrade defense chemicals and reduce their adverse effects on an insect defoliator. Oecologia 175, 901-910. Mason, C.J., Rubert-Nason, K.F., Lindroth, R.L., Raffa, K.F., 2015. Aspen defense chemicals influence midgut bacterial community composition of gypsy moth. J. Chem. Ecol. 41, 75-84. McLean, S., Pass, G.J., Foley, W.J., Brandon, S., Davies, N.W., 2001. Does excretion of secondary metabolites always involve a measurable metabolic cost? Fate of plant antifeedant salicin in common brushtail possum, Trichosurus vulpecula. J. Chem. Ecol. 27, 1077-1089. Nijhout, H.F., 1975. Excretory role of the midgut in larvae of the tobacco hornworm, Manduca $\operatorname{sexta}($ L.). J. Exp. Biol. 62, 221-230.

Novoselov, A., Becker, T., Pauls, G., von ReuSs, S.H., Boland, W., 2015. Spodoptera littoralis detoxifies neurotoxic 3-nitropropanoic acid by conjugation with amino acids. Insect Biochem, Mol. Biol. 63, 97-103.

Opitz, S.E.W., Müller, C., 2009. Plant chemistry and insect sequestration. Chemoecology 19, 117-154.

641 Pearl, I.A., Darling, S.F., 1970. The structures of salicortin and tremulacin. Tetrahedron Lett. $64211,3827-3830$.

Pentzold, S., Zagrobelny, M., Rook, F., Bak, S., 2014. How insects overcome two-component plant chemical defence: plant $\beta$-glucosidases as the main target for herbivore adaptation. Biol. Rev. 89, 531-551.

Pourcel, L., Routaboul, J.M., Cheynier, V., Lepiniec, L., Debeaujon, I., 2007. Flavonoid oxidation in plants: from biochemical properties to physiological functions. Trends Plant Sci. 12, 29-36.

Ruuhola, T., Julkunen-Tiitto, R., Vainiotalo, P., 2003. In vitro degradation of willow salicylates. J. Chem. Ecol. 29, 1083-1097.

Ruuhola, T., Tikkanen, O.P., Tahvanainen, J., 2001. Differences in host use efficiency of larvae of a generalist moth, Operophtera brumata on three chemically divergent Salix species. J. Chem. Ecol. 27, 1595-1615.

654 Sasai, H., Ishida, M., Murakami, K., Tadokoro, N., Ishihara, A., Nishida, R., Mori, N., 2009. 655 Species-specific glucosylation of DIMBOA in larvae of the rice armyworm. Biosci. Biotech. 656 Biochem. 73, 1333-1338.

657 Schramm, K., Vassao, D.G., Reichelt, M., Gershenzon, J., Wittstock, U., 2012. Metabolism of 658 glucosinolate-derived isothiocyanates to glutathione conjugates in generalist lepidopteran 659 herbivores. Insect Biochem. Mol. Biol. 42, 174-182. 
Shroff, R., Vergara, F., Muck, A., Svatos, A., Gershenzon, J., 2008. Nonuniform distribution of

661 glucosinolates in Arabidopsis thaliana leaves has important consequences for plant defense.

662 PNAS 105, 6196-6201.

663 Shyamala, M.B., 1964. Detoxification of benzoate by glycine conjugation in the silkworm, 664 Bombyx mori L. J. Insect Physiol. 10, 385-391.

665 Sonowal, R., Nandimath, K., Kulkarni, S.S., Koushika, S.P., Nanjundiah, V., Mahadevan, S., 666 2013. Hydrolysis of aromatic beta-glucosides by non-pathogenic bacteria confers a chemical 667 weapon against predators. Proc. R. Soc. B-Biol. Sci. 280, 20130721.

668 Sorensen, J.S., Dearing, M.D., 2006. Efflux transporters as a novel herbivore 669 countermechanism to plant chemical defenses. J. Chem. Ecol. 32, 1181-1196.

670 Stauber, E.J., Kuczka, P., van Ohlen, M., Vogt, B., Janowitz, T., Piotrowski, M., Beuerle, T., 671 Wittstock, U., 2012. Turning the 'mustard oil bomb' into a 'cyanide bomb': aromatic 672 glucosinolate metabolism in a specialist insect herbivore. PLoS One 7, e35545.

673 Strauss, A.S., Peters, S., Boland, W., Burse, A., 2013. ABC transporter functions as a 674 pacemaker for sequestration of plant glucosides in leaf beetles. Elife 2, e01096.

675 Terada, H., 1990. Uncouplers of oxidative phosphorylation. Environ. Health Perspect. 87, 213676218.

677 Visanuvimol, L., Bertram, S.M., 2011. How dietary phosphorus availability during 678 development influences condition and life history traits of the cricket, Acheta domesticus. J. 679 Insect Sci. 11: 63.

680 Wouters, F.C., Reichelt, M., Glauser, G., Bauer, E., Erb, M., Gershenzon, J., Vassao, D.G., 681 2014. Reglucosylation of the benzoxazinoid DIMBOA with inversion of stereochemical 682 configuration is a detoxification strategy in lepidopteran herbivores. Angew. Chem. 126, $683 \quad 11502-11506$.

684 Zhang, Y.E., Ma, H.J., Feng, D.D., Lai, X.F., Chen, Z.M., Xu, M.Y., Yu, Q.Y., Zhang, Z., 685 2012. Induction of detoxification enzymes by quercetin in the silkworm. J. Econ. Entomol. $686105,1034-1042$.

687 Zhang, Z.J., Elser, J.J., Cease, A.J., Zhang, X.M., Yu, Q., Han, X.G., Zhang, G.M., 2014. 688 Grasshoppers regulate N:P stoichiometric homeostasis by changing phosphorus contents in 689 their frass. PLoS One 9, e103697.

690 Zhen, Y., Aardema, M.L., Medina, E.M., Schumer, M., Andolfatto, P., 2012. Parallel 691 molecular evolution in an herbivore community. Science 337, 1634-1637. 
692 Zhu, J.J., Withers, S.G., Reichardt, P.B., Treadwell, E., Clausen, T.P., 1998. Salicortin: a 693 repeat-attack new-mechanism-based Agrobacterium faecalis beta-glucosidase inhibitor. 694 Biochem. J. 332, 367-371. 
Table 1: Occurrence of Lymantria dispar salicinoid metabolites in other insect herbivores species that feed on poplar. All the lepidopterans studied 697 were analyzed in their larval stages, while $C$. populi was analyzed as an adult. Feces extracts were analyzed by LC/MS and LC/MS/MS. + detected, 698 not detected, ACC, N-acetylcysteine.

\begin{tabular}{|c|c|c|c|c|c|c|c|c|}
\hline Family & Species & Saligenin & Salicin & $\begin{array}{c}\text { Salicin } \\
\text { phosphate }\end{array}$ & $\begin{array}{l}\text { Catechol } \\
\text { glucoside }\end{array}$ & $\begin{array}{l}\text { Catechol } \\
\text { glucoside } \\
\text { phosphate }\end{array}$ & $\begin{array}{c}\text { Catechol } \\
\text { ACC adduct }\end{array}$ & $\begin{array}{c}\text { Hippuric } \\
\text { acid }\end{array}$ \\
\hline Lymantriidiae & Lymantria dispar & + & + & + & + & + & + & + \\
\hline Geometridae & Selenia dentaria & + & + & - & + & - & + & + \\
\hline Lasiocampidae & Macrothylacia rubi & + & + & - & + & - & - & + \\
\hline Lymantriidiae & Orgyia antiqua & + & + & + & + & + & - & + \\
\hline Noctuidae & Scoliopteryx libatrix & + & + & - & + & - & - & + \\
\hline Noctuidae & Catocala nupta & + & + & - & + & - & - & + \\
\hline Noctuidae & Conistra vacinii & + & + & - & + & - & - & + \\
\hline Notodontidae & Phalera bucephala & + & + & - & + & - & - & + \\
\hline Notodontidae & Notodonta ziczac & + & + & - & + & - & - & + \\
\hline Notodontidae & Cerura vinula & + & + & - & + & - & + & + \\
\hline Sphingidae & Laothoe populi & + & + & - & + & - & - & + \\
\hline $\begin{array}{c}\text { Chrysomelidae } \\
\text { (Coleoptera) }\end{array}$ & Chrysomela populi & + & - & - & + & - & - & + \\
\hline
\end{tabular}


702 Representative LC/MS/MS chromatograms of feces extracts of Lymantria dispar caterpillars 703 fed artificial diet (control) or artificial diet spiked with salicin, salicortin or tremulacin. Each chromatogram contains the superimposed multiple reaction monitoring (MRM) ion traces of the seven salicinoid metabolites identified. The scaling is uniform within the traces for each metabolite but not between metabolites because of large differences in metabolite abundance. Structures of the metabolites and their corresponding precursors and metabolic intermediates are shown next to the chromatograms. Numbers indicate the peak identity $(1=$ salicin phosphate, 2 = salicin, $3=$ saligenin, $4=$ catechol glucoside phosphate, $5=$ catechol glucoside, 6 = catechol acetyl cysteine adduct, 7 = hippuric acid). HCC, hydroxyl cyclohexanone carboxylic acid.

712

Figure 2 Salicinoid metabolite concentrations in different organs of gypsy moth caterpillars before $(0 \mathrm{~h})$, shortly after $(3 \mathrm{~h})$ and long after $(24 \mathrm{~h})$ the beginning of a 90 min feeding period on Populus tremula x tremuloides foliage. Naïve caterpillars (white bars) had no preliminary experience with dietary salicinoids while experienced (grey bars) caterpillars had been allowed to eat poplar foliage for 4 days. Bars represent mean \pm SE of $6(0 \mathrm{~h})$ or 20 replicates $(3 \mathrm{~h}$ and $24 \mathrm{~h}$ ), respectively. Asterisks indicate significance of general least square model testing the effect of diet treatment (D), time after feeding (T) and their interaction $(\mathrm{D} x \mathrm{~T}),{ }^{*} \mathrm{P} \geq 0.05$, ** $\mathrm{P} \geq 0.01, * *_{-} \mathrm{P} \geq 0.001, \mathrm{~ns}=$ non significant.

Figure 3 Recovery of salicinoid metabolites from Lymantria dispar caterpillars after a $2 \mathrm{~h}$ feeding bout on P. tremula $\mathrm{x}$ tremuloides foliage. Metabolites are grouped according to the structural moiety they are derived from (Fig. 1). Caterpillars had been previously fed for 4 days on poplar foliage (gray bars) or artificial diet (white bars). Recoveries are calculated as percent of the total amount of each moiety present in foliage ingested on a molar basis. The bars labeled "unrecovered" indicate the percentage of each moiety not recovered in the total pool of identified metabolites. Bars represent the mean of 20 replicates \pm SE. Asterisks indicate significant differences between the treatments, based on a student's T-test $\left(* \mathrm{p} \geq 0.05,{ }^{* *} \mathrm{p} \geq\right.$ $0.01, *_{-} \mathrm{p} \geq 0.001, \mathrm{~ns}=$ non significant). ACC-catechol, $\mathrm{N}$-acetylcysteine catechol conjugate. 
733 Figure 4 Lymantria dispar caterpillar weight gain and survival on artificial diet supplement 734 with salicin $(200 \mu \mathrm{mol} / \mathrm{g} \mathrm{FW})$, catechol $(150 \mu \mathrm{mol} / \mathrm{g} \mathrm{FW})$, benzoic acid $(50 \mu \mathrm{mol} / \mathrm{g} \mathrm{FW})$, a 735 mixture of the three compounds and a control treatment without additives. Weight gain was 736 compared using a linear mixed effect model and was significantly influenced by time and diet 737 (linear mixed effect model, both $\mathrm{P}<0.001$ ). Significant differences among individual 738 treatments determined by model reduction are indicated as superscript letters in the legend. 739 Weight gain graphs represent the mean \pm SE of 10 replicate Petri dishes. Survival was analyzed 740 by Kaplan-Meier analysis and the results are displayed as superscript letters. 


\section{Tables}

Table 1: Occurrence of Lymantria dispar salicinoid metabolites in other insect herbivores species that feed on poplar. All are lepidopteran species, except Chrysomela populi, which is a coleopteran. All the lepidopterans studied were analyzed in their larval stages, while $C$. populi was analyzed as an adult. Feces extracts were analyzed by LC/MS and LC/MS/MS. + detected, - not detected, ACC, N-acetylcysteine.

\begin{tabular}{|c|c|c|c|c|c|c|c|c|}
\hline Family & Species & Saligenin & Salicin & $\begin{array}{c}\text { Salicin } \\
\text { phosphate }\end{array}$ & $\begin{array}{l}\text { Catechol } \\
\text { glucoside }\end{array}$ & $\begin{array}{l}\text { Catechol } \\
\text { glucoside } \\
\text { phosphate }\end{array}$ & $\begin{array}{c}\text { Catechol } \\
\text { ACC } \\
\text { adduct }\end{array}$ & $\begin{array}{c}\text { Hippuric } \\
\text { acid }\end{array}$ \\
\hline Lymantriidiae & Lymantria dispar & + & + & + & + & + & + & + \\
\hline Geometridae & Selenia dentaria & + & + & - & + & - & + & + \\
\hline Lasiocampidae & Macrothylacia rubi & + & + & - & + & - & - & + \\
\hline Lymantriidiae & Orgyia antiqua & + & + & + & + & + & - & + \\
\hline Noctuidae & Scoliopteryx libatrix & + & + & - & + & - & - & + \\
\hline Noctuidae & Catocala nupta & + & + & - & + & - & - & + \\
\hline Noctuidae & Conistra vacinii & + & + & - & + & - & - & + \\
\hline Notodontidae & Phalera bucephala & + & + & - & + & - & - & + \\
\hline Notodontidae & Notodonta ziczac & + & + & - & + & - & - & + \\
\hline Notodontidae & Cerura vinula & + & + & - & + & - & + & + \\
\hline Sphingidae & Laothoe populi & + & + & - & + & - & - & + \\
\hline $\begin{array}{c}\text { Chrysomelidae } \\
\text { (Coleoptera) }\end{array}$ & Chrysomela populi & + & - & - & + & - & - & + \\
\hline
\end{tabular}


FIGURES
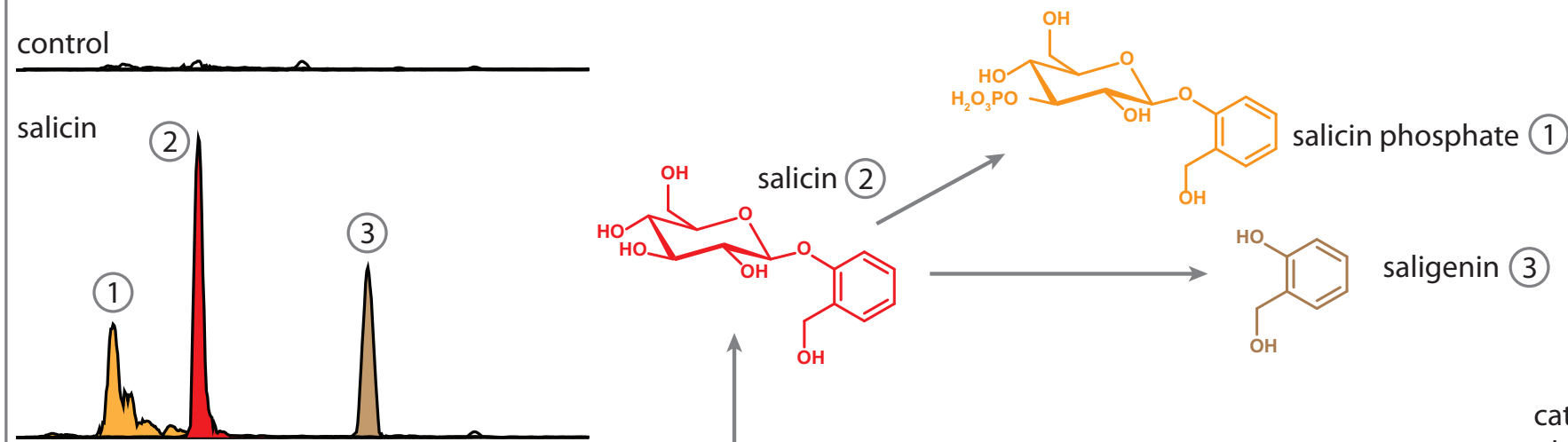

salicortin
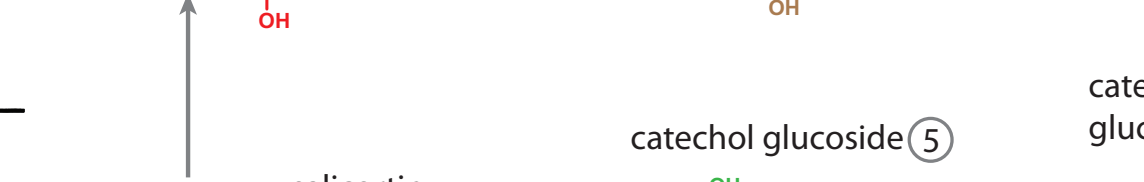

catechol

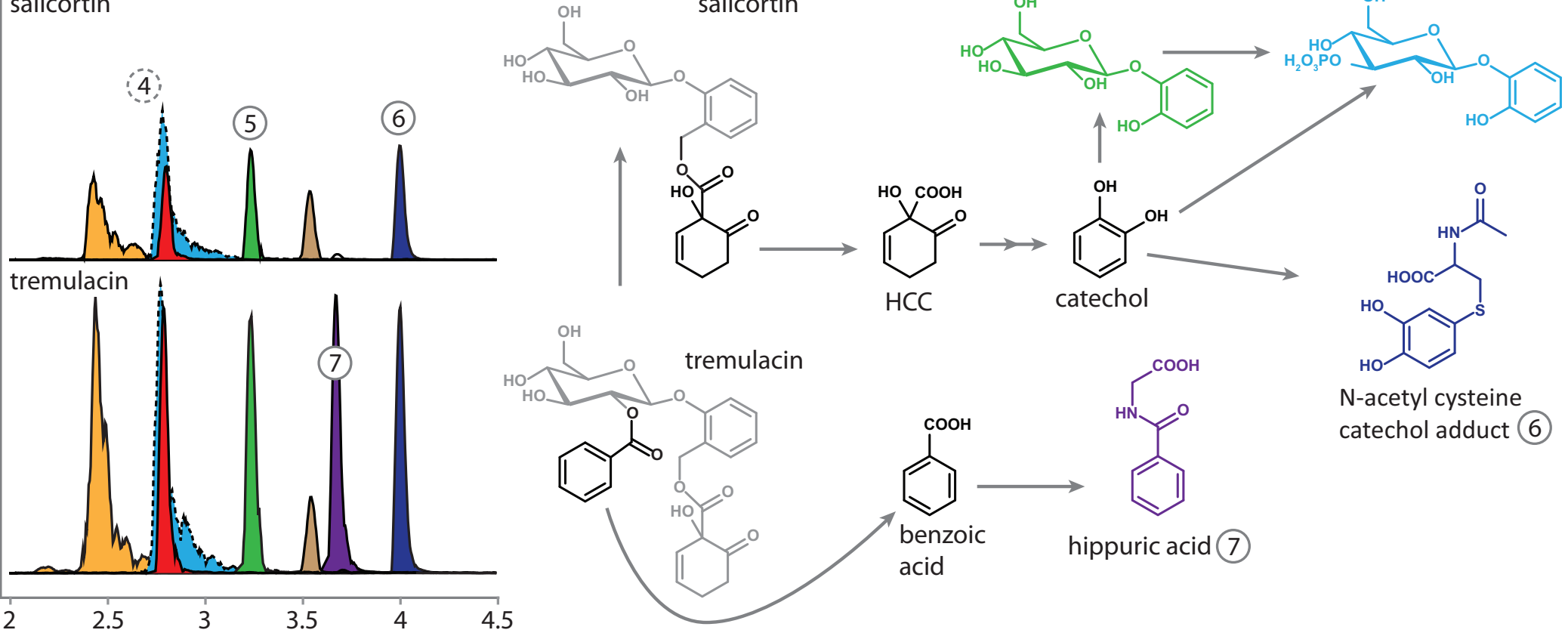



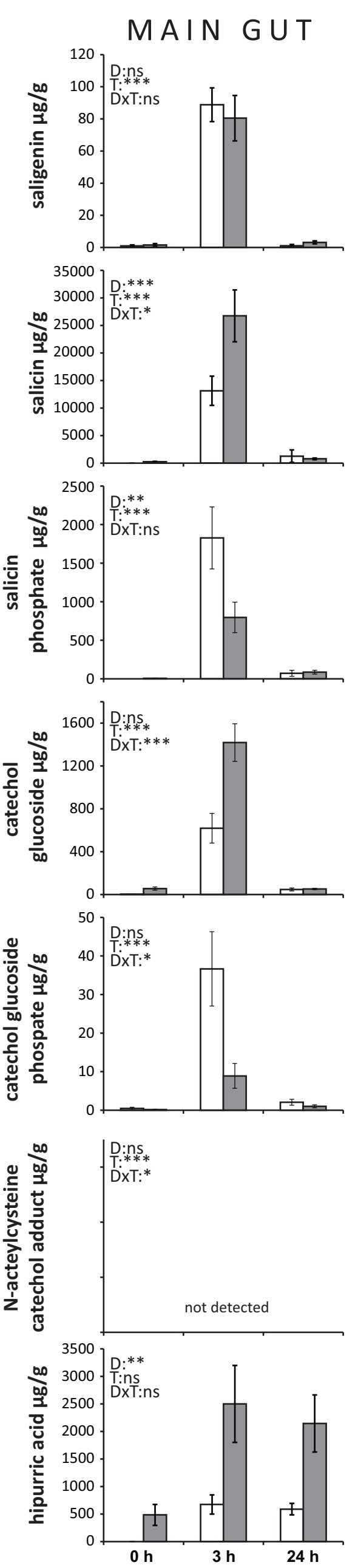
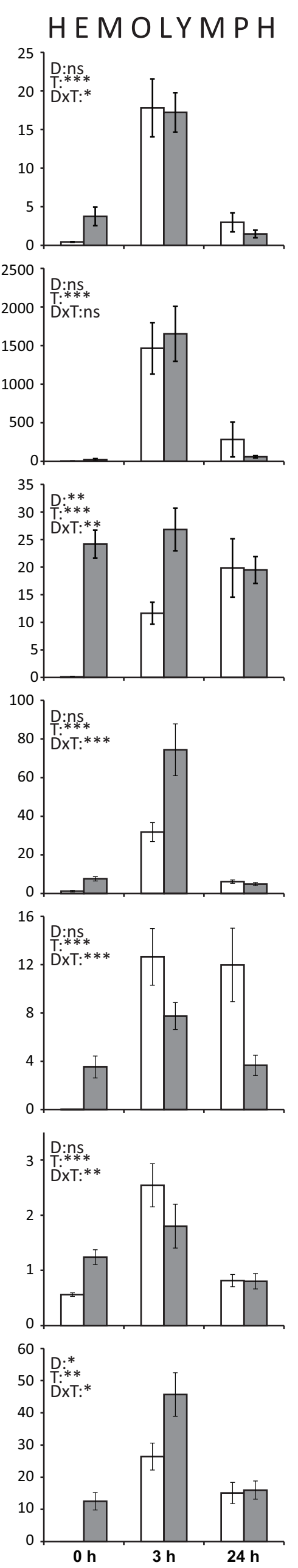

MALPIGHIAN

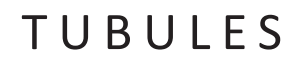

not detected
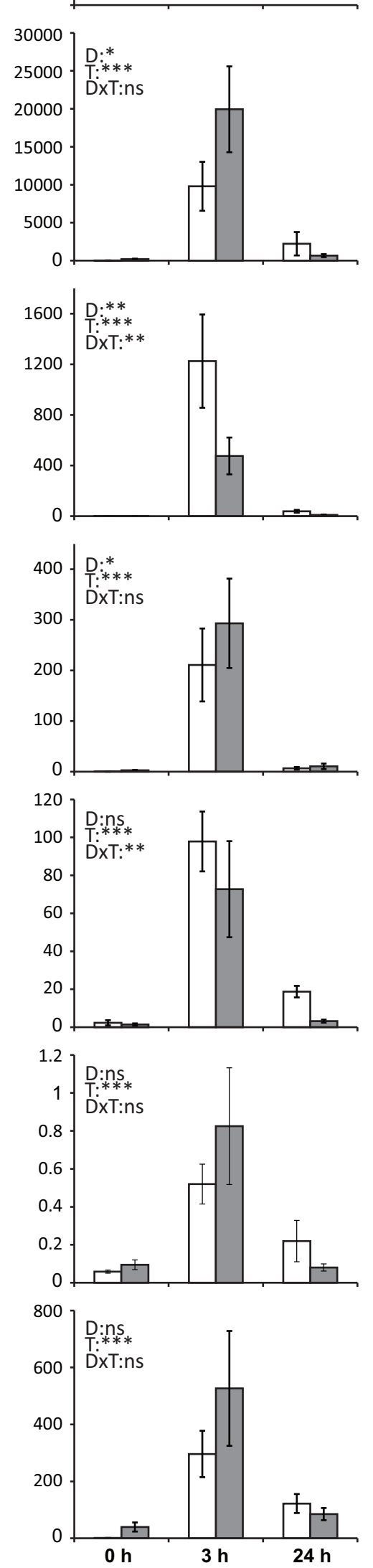

H I N D G U T
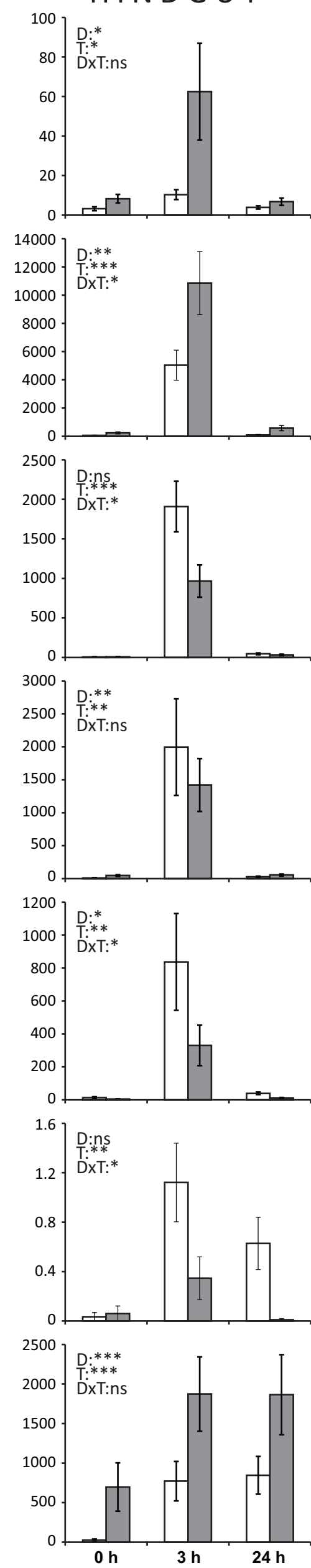
Figure 3

FROM SALICIN MOIETIES

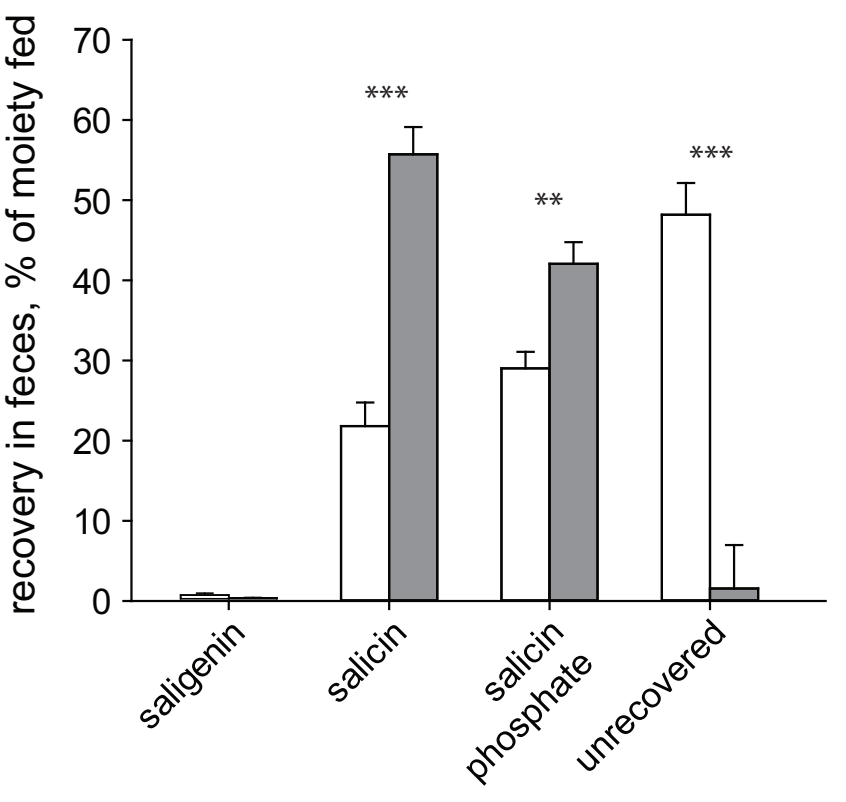

FROM HCC MOIETIES

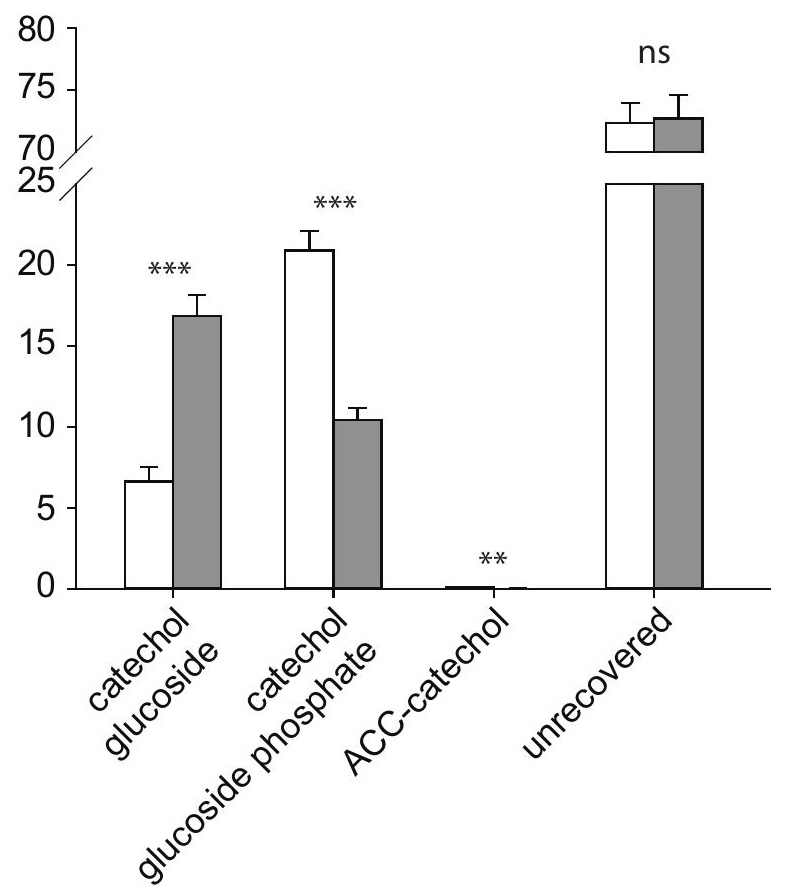

FROM BENZOYL MOIETIES

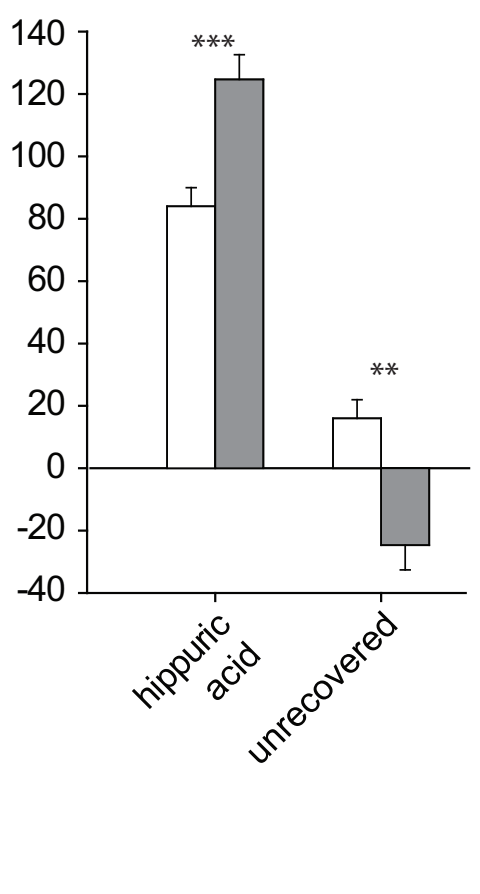


Figure 4
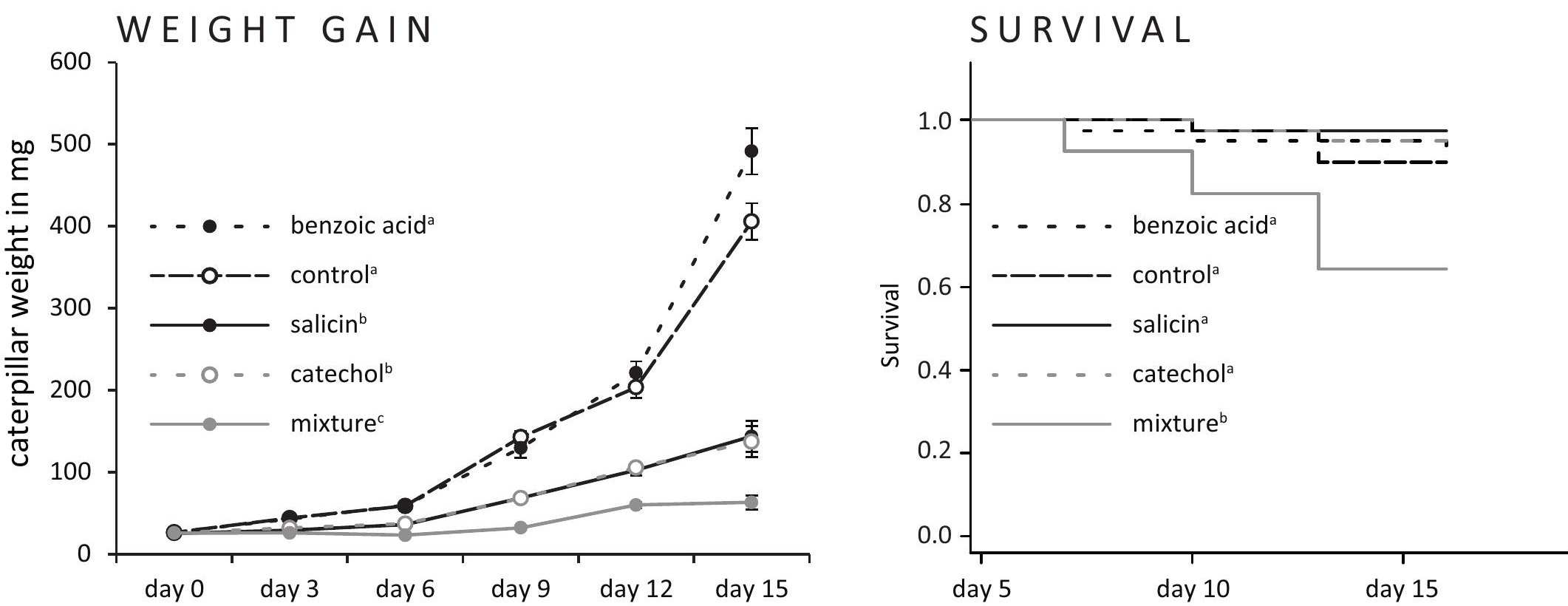


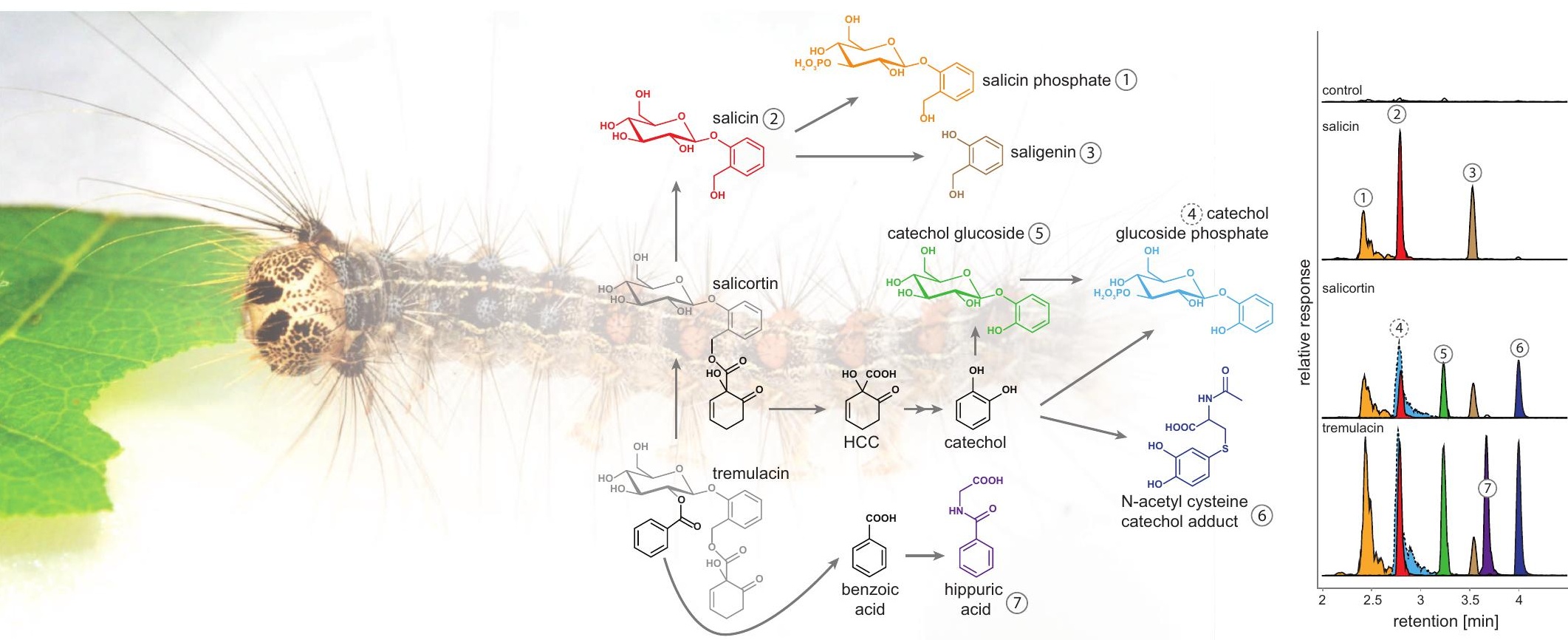

